\title{
GIS based mapping of spatio-temporal distribution pattern of ribbonfish Trichiurus lepturus (Linnaeus, 1758) along Saurashtra coast, India
}

\author{
P. ABDUL AZEEZ ${ }^{1}$, K. MOHAMMED KOYA ${ }^{2}$, K. L. MATHEW ${ }^{1}$, G. S. TEMKAR ${ }^{1}$ \\ AND R. A. KHILERI ${ }^{1}$ \\ ${ }^{1}$ College of Fisheries, Junagadh Agricultural University, Veraval, Gujarat - 362 269, India \\ ${ }^{2}$ Veraval Regional Centre, ICAR-Central Marine Fisheries Research Institute, Veraval - 362 269, Gujarat, India \\ e-mail: azeez.cr7@gmail.com
}

\begin{abstract}
Identification of spatio-temporal distribution of fish species represents fundamental information for stock assessment which in turn is essential for formulation of fishery management plans as well as for GIS based decision making. This study investigated the spatio-temporal distribution and abundance of different life stages of ribbonfish, Trichiurus lepturus (Linnaeus, 1758) off Saurashtra coast. Geographical coordinates of fishing and allied information on the time of fishing, depth of the fishing area as well as catch details were collected using a structured schedule, from selected trawlers operated from Veraval. Information was mapped using a GIS software to get the spatio-temporal distribution of the species. It was observed that juveniles were more abundant along the south Saurashtra coast whereas subadults and adults showed a discontinuous distribution with abundance in the waters off south Saurashtra as well as north Saurashtra coasts.
\end{abstract}

Keywords: Abundance, Distribution, GIS, Ribbonfish, Saurashtra coast, Trichiurus lepturus

\section{Introduction}

Ribbonfish represents one of the major components of exploited marine fishery resources along Saurashtra coast (Ghosh et al., 2009). Presently, Trichiurus lepturus forms the major component of the ribbonfish catches along Saurashtra coast, while the other species of ribbonfishes viz., Lepturacanthus savala and Eupleurogrammus muticus occur occasionally. Total landings of ribbonfishes in Gujarat was about 91,729 t during the year 2012. Mechanised multiday trawlers alone contributed to about $82.5 \%$ of the total ribbonfish landings and the remaining by single day trawlers, mechanised dolnetters and gillnetters (CMFRI, 2013).

Information regarding temporal as well as spatial occurance of $T$. lepturus is critical for resource management. Fish populations show spatial and temporal repartition of life stages (Harden-Jones, 1968). The shift in habitat of each developmental stage i.e., areas of juvenile development, subadult and adult grounds, indicates that species change their ground during the life cycle. In some species, these areas can be geographically separated (Koubbi et al., 2006). Geographical information system (GIS) is a potential and powerful tool in fisheries management and ecosystem studies. It is possible to analyse and map the distribution of species with GIS (Valavanis et al., 2002; 2004).
Application of GIS in Indian fisheries sector has been considerably slow when compared to other countries. The studies on spatio-temporal distribution of marine fishes using GIS in the Indian context is limited to the works of Selvaraj et al. (2007) and Dineshbabu et al. (2012). Although information is available on the length-weight relationship, sex ratio, maturity, spawning season, food and feeding habits and population dynamics of T. lepturus from the coast of Saurashtra (Ghosh et al., 2009; Fofandi, 2012; CMFRI, 2013; Avinash, et al., 2014), no information is available on its spatio-temporal distribution. The present investigation was undertaken to study the spatio-temporal distribution and to map the distribution of T. lepturus along Saurashtra coast by overlaying the Global Positioning System (GPS) linked catch per unit effort (CPUE) data using a GIS software.

\section{Materials and methods}

\section{Data collection}

The study was conducted from March 2013 to February 2014. Data on the catch at each of the fishing stations with the details of latitude and longitude of shooting the net, date and time of fishing, depth of the fishing area, trawling speed, latitude and longitude of hauling the net, total catch in the haul and total as well as size-wise catch of ribbonfishes in the haul were collected from the trawlers. The skipper of the identified trawler 
was instructed to provide the haul-wise data on the catch in a structured and pre-tested data collection schedule. The collection of data from such vessels was restricted to the fishing coordinates-wise catch information for the study on spatio-temporal distribution of T. lepturus off Saurashtra coast. The spatial data thus collected were used as input for the GIS study as described by Graham et al. (2002). Two multiday trawlers and one single day trawler operated from Veraval Fishing Harbour (Fig. 1) were selected for the study.

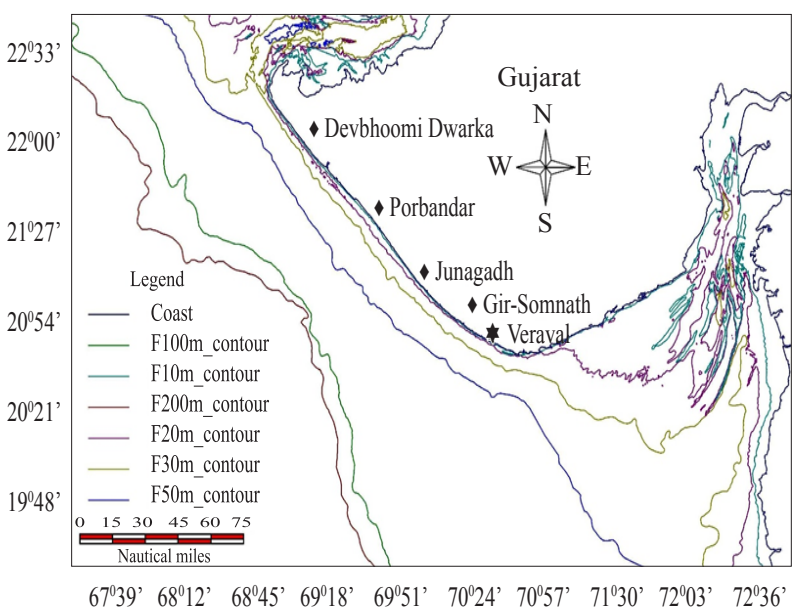

Fig. 1. Study area and major coastal districts of Saurashtra

The total number of hauls with geo-referenced data collected from trawlers during summer (March to May), post-monsoon (August to November) and winter (December to February) seasons were 122, 171 and 149 respectively. Fishing season in Saurastra is of nine months from September to May. Fishing activities are prohibited from 10 June to 15 August as per the Marine Fishing Regulation Act of Gujarat (2003) and also due to monsoon during which rough conditions prevail in the sea. Trawl nets were towed by fishermen for $3 \mathrm{~h} 5 \mathrm{~min}$ (annual average) at a speed of 3.03 knots. The shooting points, hauling points and the speed of trawling were recorded from the GPS fitted in the trawler and the depth of the area of fishing was measured using the fish finder fitted onboard.

Life history stages of T. lepturus were classified to disaggregate the biomass of the stock and to provide results on each stage of its life history. Life history stages were classified based on maturity stages. Small sized or juvenile fish (about $<60 \mathrm{~cm}$ total length, TL) were characterised by immature gonadal development, subadults (about $60-75 \mathrm{~cm}$ TL) were predominantly immature and adults $(>75 \mathrm{~cm} \mathrm{TL})$ were sexually mature. Number, size and individual weight of the species in the sample were recorded to study the life stages of the species, especially juveniles, subadults and adults, which would enable to understand the spatio-temporal distribution of the fishes as well as its distribution pattern at different life stages (Dineshbabu et al., 2012).

Database was created for the three main seasons in a year: summer, post-monsoon and winter. Observations during monsoon had to be omitted because the data were incomplete due to trawling ban. Haul- wise catch data were fed into Microsoft excel 1997-2003 format as queries. Attribute features included geographical position of shooting and hauling (latitude and longitude) of trawling operation, depth of operation and size-wise catch details of ribbonfish in CPUE (juveniles, subadults and adults), and were added in queries against the respective haul and the date of trawling. Records of all the sampling stations had a unique ID number (haul number) for querying and analyses.

\section{Mapping}

GeoMedia Professional 2014 v14. was used to create a georeferenced map for the study. Coastline and bathymetry maps were digitised from available nautical maps. For mapping, all the queries and bathymetric map were integrated into GIS and mapped by interpolating the data. Interpolations were made using geo-statistics, which has assigned a value at unsampled locations to be estimated from sparse sampled data points (Rivoirard et al., 2000). The interpolated data were grouped into different classes and mapped.

\section{Results and discussion}

The spatio-temporal distribution pattern of T. lepturus stock off Saurashtra coast over the year followed a clear pattern. Various factors such as the physico-chemical parameters of the sea, depth as well as availability of food influence the abundance of different life stages viz., the juveniles, subadults and adults of T. lepturus. The distribution of juveniles of the species during summer, post-monsoon and winter is given in Fig. $2(a, b, c)$. It revealed that the distribution of juveniles of this species in all the three seasons had almost the same trend and the abundance along Surashtra coast remained steadily high, especially along the south Suarashtra coast (below 20 $48^{\prime} \mathrm{N}$ ) at a depth above $30 \mathrm{~m}$ in summer and during post-monsoon and in winter, the abundance was observed above $50 \mathrm{~m}$. Southern Saurashtra coast is close to the mouth area of Gulf of Kambhat, a high productive zone influenced by the large amount of nutrients brought in by many perennial and seasonal rivers and high tidal range. This is a detritus rich zone that provides a 


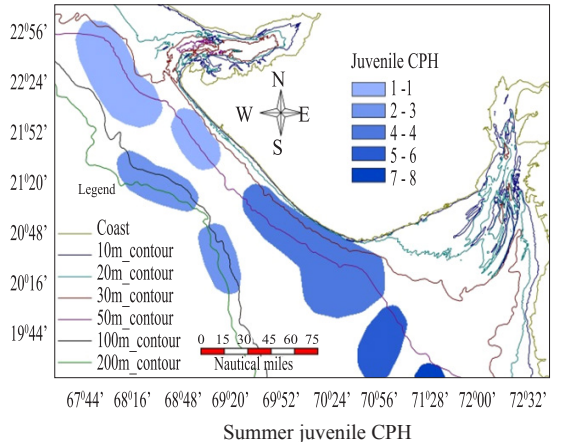

(a)

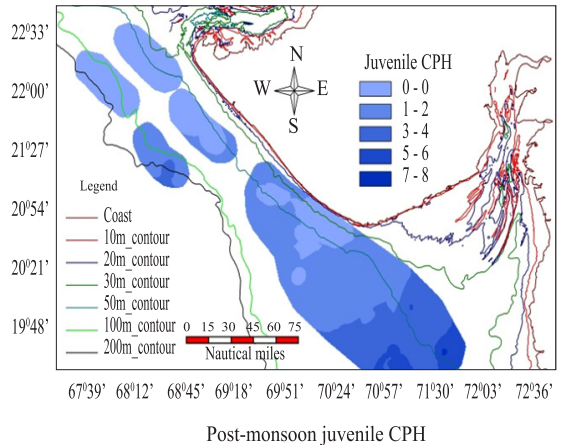

(b)

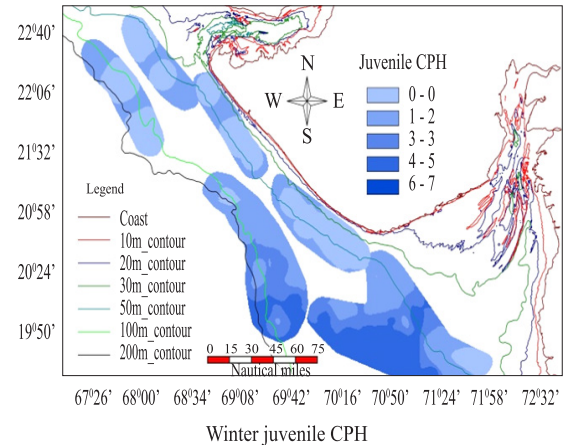

(c)

Fig. 2. Distribution of juveniles of T. lepturus during (a): summer, (b): Post-monsoon, (c): Winter

preferred feeding habitat for Acetes spp. (Deshmukh, 2002), leading to their higher levels of abundance. Acetes spp. is regarded as the most favoured food item of the ribbonfishes (Lazarus and Sarma, 1991; Reuben et al., 1997; Khan, 2006; Avinash, 2009). The results of the present study revealed that the major ribbonfish catch during March-May comprised of juveniles. The period corresponds to the major recruitment period in the region (Ghosh et al., 2009; Fofandi, 2012).

Harden-Jones (1968) described how the spatial distribution of fish during their different stages of development can be superimposed on oceanographic features. For some species, spawning grounds, nurseries and adults are geographically separated as a function of the water currents. The distribution of subadults of the species during summer, post-monsoon and winter is given in Fig. 3(a, b, c). The abundance of subadults along Saurashtra coast continued to increase towards both northern and southern side. It was highest (19-23 $\left.\mathrm{kg} \mathrm{h}^{-1}\right)$ in the offshore (>50 $\mathrm{m}$ depth) off Devbhoomi Dwarka, inshore (30-50 m depth) off Porbandar and south to Gir-Somnath districts. The comparison of spatio-temporal distribution of juveniles and subadults revealed that the subadults were more common along the northern region of Saurashtra coast i.e., off Devbhoomi Dwarka District.
Ribbonfish catch was dominated by subadult stage throughout the year than other two groups, but in winter the average CPUE was highest i.e., $48 \mathrm{~kg} \mathrm{~h}^{-1}$. Thus the study concurs the previous findings that the subadults dominated T. lepturus catch by trawlers as compared to juveniles and adults (Ghosh et al., 2009; Avinash, 2009). Post-monsoon period is the most productive in terms of catch and catch rate coinciding with an increased fishing activity. In Gujarat there exists prohibition for fishing using all crafts and gears during June-August as per the Gujarat Marine Fishing Regulation Act and fishing is suspended during the period which probably contributes to the high catch and catch rates during the post-monsoon (Ghosh et al., 2009). This is the reason attributed for the dominance of subadults during post-monsoon and early winter months as compared to that in summer.

The abundance of adults of the species during summer, post-monsoon and winter is shown in Fig. 4(a, b, c). Higher abundance of adults was observed further south off Gir-Somnath District (below 1944' N) except during post-monsoon. In post-monsoon, the higher abundance was observed in deeper waters (100-200 m depth) off Porbandar District. The study indicates that the contribution of juveniles and adults in the total catch of T. lepturus was at moderate level with the catch rate of

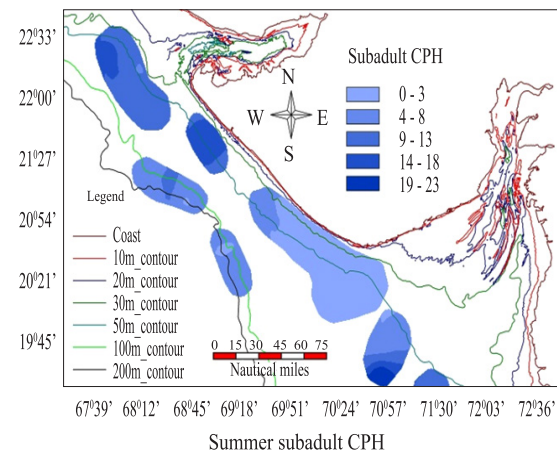

(a)

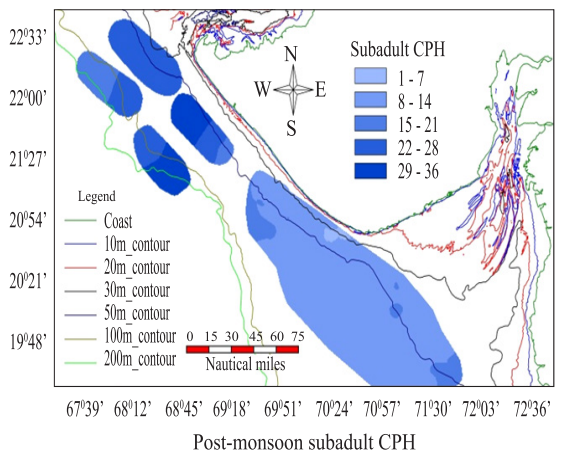

(b)

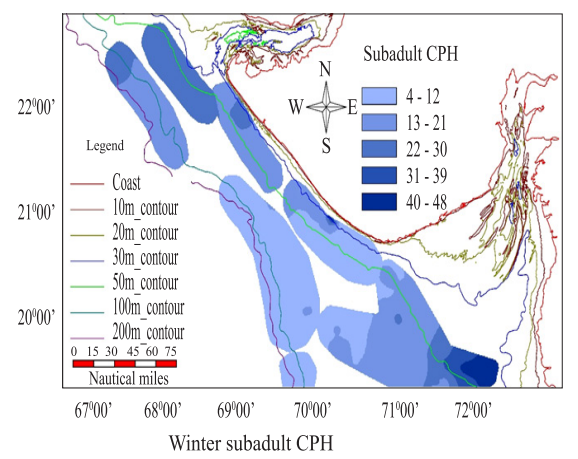

(c)

Fig. 3. Distribution of subadults of T. lepturus during (a): summer, (b): Post-monsoon, (c): Winter 


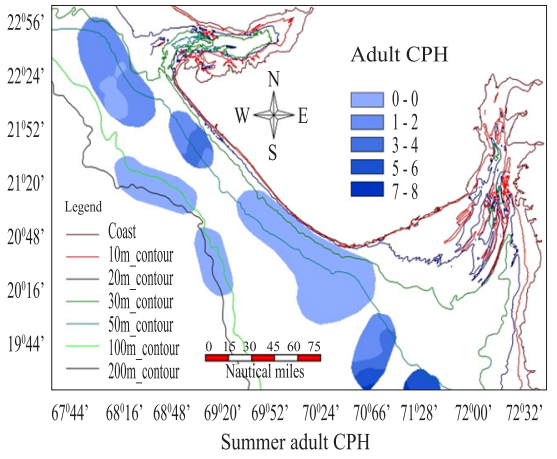

(a)

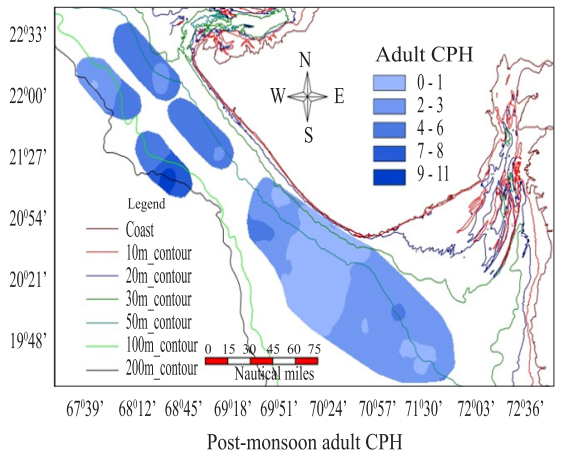

(b)

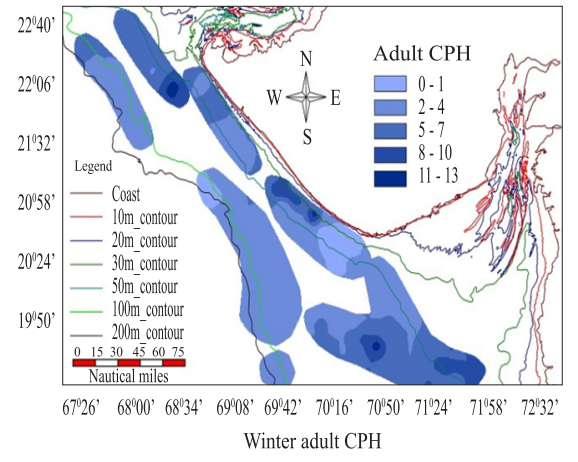

(c)

Fig. 4. Distribution of adults of T. lepturus during (a): summer, (b): Post-monsoon, (c): Winter

adults dominating in the deeper waters ( $>50 \mathrm{~m}$ depth) during winter. Winter is known to be the peak breeding season for the species along Saurashtra coast. Breeding migration of adults to deeper waters could explain the elevated catch rates from depth $>50 \mathrm{~m}$ (Avinash, 2009). Near absence of spawning fish in the commercial catches and the scarcity of eggs and larvae in the routine plankton collections have indicated that $T$. lepturus moves away to deeper waters for breeding (Prabhu, 1950; Narasimham, 1972; James et al., 1986). But the presence of spawners in various stages of maturity in the fishery during breeding season could be an indication that the breeding grounds is not far away from the fishing grounds. Fishing grounds, with a depth range of 5-30 $\mathrm{m}$ are not considered as the spawning grounds of T. Lepturus (Narasimham, 1972). Bapat et al. (1982) have recorded running specimens in good percentage from the depth zone of 91-125 m. T. lepturus from Veraval waters spawned throughout the year with its peak during December-March (Avinash, 2009).

The spatial abundance maps produced in this study do not account for many complex relationships between species and environmental variables. However, in the absence of a more complete knowledge of the nature of these relationships and the spatial scales at which they operate, the catch and effort data approach presents a relatively effective method for conducting a first-phase identification of likely distributions of the species.

The findings of this study confirm that juvenile grounds are in the waters along the south Saurashtra coast and hence there is a need to divert the fishing pressure to the waters off south Saurashtra and north Saurashtra coasts where subadults and adults are abundant, in order to realise better recruitment to the fishery. We found the fish migrated to deeper waters for breeding and therefore the abundance of adults was relatively high in deeper waters, especially during winter. The results of this study would be beneficial to both resource managers and fishers to understand the spatio-temporal distribution with respect to its life stages. Presently, ribbonfish exploited by trawlers were only taken into consideration and in future the data from different fishing gear for all the resources and oceanographic parameters could also be incorporated to make their spatio-temporal distribution map with respect to life stages for effective harvest, GIS based decision making, conservation and management.

\section{Acknowledgements}

The authors thank Dr. A. Y. Desai, Dean and Principal, College of Fisheries, Veraval, Junagadh Agricultural University, Gujarat for granting permission to carry out the work. The authors also thank the Director, ICAR-Central Marine Fisheries Research Institute, Kochi for granting permission to carry out the work at the Veraval Regional Centre of ICAR-CMFRI, Veraval and for the technical guidance of the scientists of the Centre. The authors are grateful to Dr. A. P. Dineshbabu, Principal scientist, ICAR-CMFRI, Mangalore for sparing the bathymetric shape files. Thanks are also due to Parag Parmar, Jithesh Solanki and Mahesh for technical assistance in data collection.

\section{References}

Avinash, R. 2009. Fishery and population dynamics of Trichiurus lepturus off Veraval coast. M. F. Sc. thesis, Junagadh Agricultural University, Junagadh, India.

Avinash, R., Desai, A. Y. and Ghosh, S. 2014. Population dynamics of Trichiurus lepturus (Linnaeus, 1758) off Veraval. Indian J. Fish., 61: 14-18.

Bapat, S. V., Deshmukh, V. M., Krishnamoorthy, B., Muthiah, C., Kagwade, P. V., Ramamirtham, C. P., Mathew, K. J., Pillai, S. K. and Mukundan, C. 1982. Fishery resources of the Exclusive Economic Zone of the north-west coast of India. Bulletin of the Central Marine Fisheries Research Institute, 33: 1-81.

CMFRI 2013. CMFRI Annual Report 2012-13. Central Marine Fisheries Research Institute, Kochi. 
Deshmukh, V. D. 2002. Biology of Acetes indicus (Milne Edwards) in Bombay waters. Indian J. Fish., 49: 379-388.

Dineshbabu, A. P., Thomas, S., Radhakrishnan, E. V. and Dinesh, A. C. 2012. Preliminary experiments on application of participatory GIS in trawl fisheries of Karnataka and its prospects in marine fisheries resource conservation and management. Indian J. Fish., 59: 15-22.

Fofandi, M. D. 2012. Population dynamics and fishery of ribbonfish (Trichiurus lepturus) of Saurastra coast. 1: 189. doi:10.4172/scientificreports. 189 .

Ghosh, S., Pillai, N. G. K. and Dhokia, H. K. 2009. Fishery and population dynamics of Trichiurus lepturus (Linnaeus) off Veraval, north-west coast of India. Indian J. Fish., 56: $241-247$.

Graham, J., Engle, S. and Recchia, M. 2002. Local knowledge and local stocks: an atlas of groundfish spawning in the Bay of Fundy. Antigonish, Nova Scotia: The Centre for Community-based Management, Extension Department, St. Francis Xavier University, Canada.

Harden-Jones, F. R. 1968. Fish migration. Edward Arnold, London, $325 \mathrm{pp}$.

James, P. S. B. R., Narasimham, K. A., Meenakshi Sundaram, P. T. and Appanna Sastry, Y. 1986. Present status of ribbonfishes of India. Special Publication, Central Marine Fisheries Research Institute, Kochi, 24: 49 pp.

Khan, M. Z. 2006. Fishery resource characteristics and stock assessment of ribbonfish, Trichiurus lepturus (Linnaeus). Indian J. Fish., 63: 1-12.

Koubbi, P., Loots, C., Cotonnec, G., Harlay, X., Grioche, A., Vaz, S., Martin, C., Walkey, M. and Carpentier, A. 2006. Spatial patterns and GIS habitat modelling of Solea solea, Pleuronectes flesus and Limanda limanda fish larvae in the eastern English Channel during the spring. Sci. Mar. 70S2: 147-157.

Lazarus, S. and Sarma, P. S. S. 1991. The resource characteristics of the ribbonfish Trichiurus lepturus at Vizhinjam, south-west coast of India. J. Mar. Biol. Ass. India, 33: 89-88.

Narasimham, K. A. 1972. Occurrence of early juveniles of ribbonfish Trichiurus lepturus Linnaeus in the Kakinada area with notes on their food. Indian J. Fish., 19: 210-214.

Prabhu, M. S. 1950. On the breeding habits of ribbonfish, Trichiurus haumela (F). Curr. Sci., 19: 213-214.

Reuben, S., Vijayakumaran, K., Achayya, P. and Prabhakar, R. V. D. 1997. Biology and exploitation of Trichiurus lepturus Linnaeus from Visakhapatnam waters. Indian J. Fish., 44: 101-110.

Rivoirard, J., Simmonds, J., Foote, K. G., Fernades, P. G. and Bez, N. 2000. Geostatistics for estimating fish abundance. Blackwell Science, Oxford, 206 pp.

Selvaraj, J. J., Biradar, R. S. and Somavanshi, V. S. 2007. Spatial and temporal patterns of demersal fish distribution in the north-west coast of India: a study using Geographic Information System (GIS). Indian J. Fish., 54: 243-249.

Valavanis, V. D., Georgakarakos, S., Kapantagakis, A., Palialexis, A. and Katarac, I. 2004. A GIS environmental modelling approach to essential fish habitat designation. Ecological Modelling, 178: 417-427.

Valavanis, V. D., Georgakarakos, S., Koutsoubas, D., Arvanitidis, C. and Haralabous, J. 2002. Development of a marine information system for cephalopod fisheries in the Greek seas (Eastern Mediterranean). Bull. Mar. Sci., 71: $867-882$. 